\title{
Response decrement to repeated shadow stimuli in the garter snake, Thamnophis radix
}

\author{
CHARLES E. FUENZALIDA, GEORGE ULRICH, and BARNEY T. ICHIKAWA \\ University of Colorado, Boulder, Colorado 80302
}

\begin{abstract}
Five plains garter snakes, Thamnophis radix, were exposed to 15 shadow stimuli followed by a nosetap and two more shadow stimuli on each of 5 successive days. Two measures of movement were taken immediately after each stimulus. Both measures indicate strong reactivity to the initial three or four shadow stimuli of each day and response decrement thereafter. The nosetap produced an unambiguous response in both measures, but, dishabituation was not evident on the subsequent two trials. The rate of habituation did not increase as a function of days.
\end{abstract}

Habituation has been demonstrated in snakes in only one study: Andry and Luttges (1972) showed that an index of CNS electrical activity decremented in the garter snake, Thamnophis radix, during repeated presentation of a visual stimulus. No behavioral correlates of this CNS change were reported. The present study was undertaken to determine if indices of overt behavior in this species also show changes which can be interpreted as habituation.

\section{METHOD}

\section{Subjects}

Five experimentally naive plains garter snakes (Thamnophis radix) served as subject. They averaged $60 \mathrm{~g}$ in weight and $40 \mathrm{~cm}$ in length.

\section{Maintenance Conditions}

Snakes were maintained in a windowless room at $22-24^{\circ} \mathrm{C}$ and with a photoperiod from 0800 to 1800 . Each animal was housed in a clear plastic cage $(18 \times 25 \times 25 \mathrm{~cm})$ which contained paper bedding, a rock, and a water cup. Feeding occurred once per week when strips of ocean perch filets were offered to each snake until satiation.

The snakes were maintained under these conditions for 52 days prior to the experiment, and each animal was handled three times during each of these weeks. Handling consisted of removing the snake from its cage and holding it gently for $5 \mathrm{~min}$.

\begin{abstract}
Apparatus
A plastic cage, identical to those serving as home cages, was mounted in a balsa frame so that the cage bottom rested on top of a Type M93ED phonograph cartridge. A constant pressure was exerted on the cartridge by the cage plus a brass counterweight. Signals arising in the cartridge as a consequence of pressure changes were driven through an amplifier and eventually into an oscilloscope. Hence, pressure changes in the cage produced by animal movements could be measured as $\mathrm{cm}$ of deflection of the oscilloscope display.
\end{abstract}

The authors wish to thank M. L. Andry for his helpful suggestions and Dr. D. A. Chiszar for the use of his laboratory and for his guidance during all phases of this work. Requests for reprints should be addressed to: $D$. A. Chiszar, Department of Psychology, University of Colorado, Boulder, Colorado 80302. This paper was sponsored by Raymond C. Miles, who takes full editorial responsibility for its contents.
The floor of the cage was marked off into $2.5-\mathrm{cm}$ squares. Accordingly, the above stabilimeter measurments were supplemented with recordings of the number of squares moved through by the subject during test trials.

A $100-W$ incandescent bulb was mounted $38 \mathrm{~cm}$ above the floor of the stabilimeter. This bulb cast sufficient light so that a shadow could easily be caused to fall on the cage floor by passing a hand between the bulb and the cage.

\section{Procedure}

A snake was placed into the stabilimeter with the light on and 2 min were allowed to pass before stimulus presentations began. Since these snakes had experienced a great deal of handling prior to the experiment, they rarely assumed the defensive posture wherein the head is tucked under one or more coils. Instead, they quickly came to rest with the head well away from the coils so that the shadow stimulus could easily be seen.

Shadow stimuli were produced in the manner described above on 15 successive trials (ITI $=10 \mathrm{sec}$ ). During ITI, one assistant recorded the oscilloscopic-display deflection and another assistant recorded the number of squares through which the snake's head traveled during the first movement to occur after the stimulus. Ten seconds after Trial 15, the snake's nose was tapped gently with a pencil and both measures were again recorded. Finally, two additional shadow trials were administered after the nosetap. This entire procedure was repeated on each of four consecutive days.

\section{RESULTS}

Figure 1 plots mean number of centimeters of oscilloscopic-display deflection (ODD) as a function of trials. Trials were summed over days for this presentation. The decrease in ODD over Trials $1-15$ was statistically reliable $(\mathrm{F}=4.95, \mathrm{df}=14 / 56, \mathrm{p}<.01)$, as was the increase between Trials 15 and $16(\mathrm{~F}=11.41$, df $=1 / 4, p<.05)$. However, performance on Trials 17 and 18 did not differ significantly from performance on Trials 14 and $15(\mathrm{~F}<1)$. The main effect of days did not attain statistical reliability, and days did not interact significantly with any of the above effects.

Figure 2 presents mean number of squares traversed by the snakes' heads just after the shadow as a function of trials. Since all effects reported for ODD were exactly the same for this measure, there is no need to elaborate 


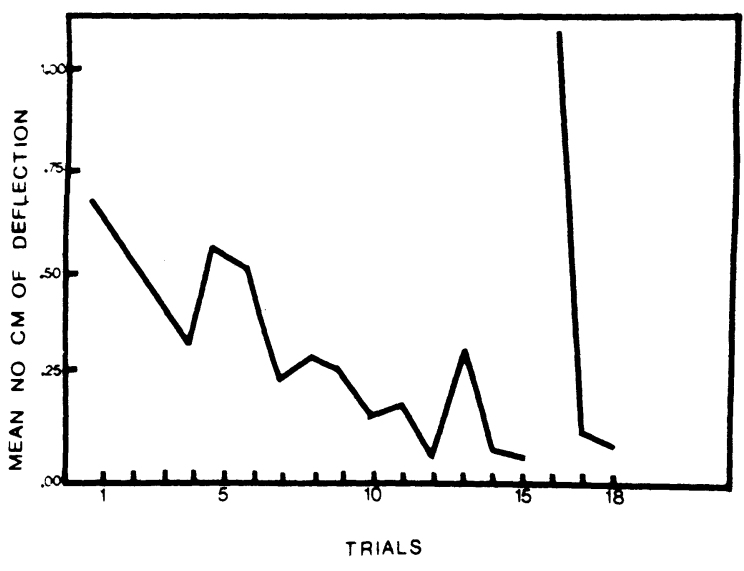

Figure 1. Mean number of centimeters of oscilloscopic-display change as a function of trials within days. This is a stabilimeter measure of the force of contraction which reveals that the snakes had essentially ceased contracting by Trial 15 .

the statistical details. In fact, the average correlation between ODD and number of squares traversed was $\mathrm{r}=.89, \mathrm{df}=70, \mathrm{p}<.01$.

\section{DISCUSSION}

It is clear that the snakes habituated to the shadow stimulus in this experiment. The possibility that the response decrement during Trials 1-15 resulted from muscular fatigue was eliminated by the fact that the snakes were capable of responding vigorously to the nosetap delivered on Trial 16. Since days produced neither main effects nor interactions in analy ses of the two dependent variables, it must be concluded that processes giving rise to within-days or short-term habituation do not automatically produce between-days or long-term habituation. Since habituation implies memory, it seems reasonable to hypothesize that Thamnophis radix is able to retain information arising from shadow stimulation across 15 consecutive (i.e., massed) trials but not across 24 -h intervals. In a similar experiment with the salamander Necturus maculosus, effects of habituation were retained for 75-90 min but not for $24 \mathrm{~h}$ (Goodman \& Weinberger, 1973), suggesting that response decrements consequent to reiterative shadow stimulation may persist at least for intermediate intervals. Although it is tempting to speculate that the absence of long-term habituation in lower vertebrates results from ineffective long-term memory substrates in these animals, an important study revealed retention of habituation beyond $24 \mathrm{~h}$ in the fish Lebistes reticulatus (Russell, 1967). Accordingly, it seems more reasonable to assume that the appearance of long-term habituation depends on such interacting factors as (1) the kind of stimulus employed, (2) the response system examined, (3) the number of stimulus presentations during the initial habituation series, (4) species, etc. Until the roles of these variables can be specified, it would be unwise to consider the absence of long-term habituation indicative of basic phyletic differences in memorial or other psychological processes.

Trials 17 and 18 were included in the present study to measure the extent to which the nosetap delivered on Trial 16

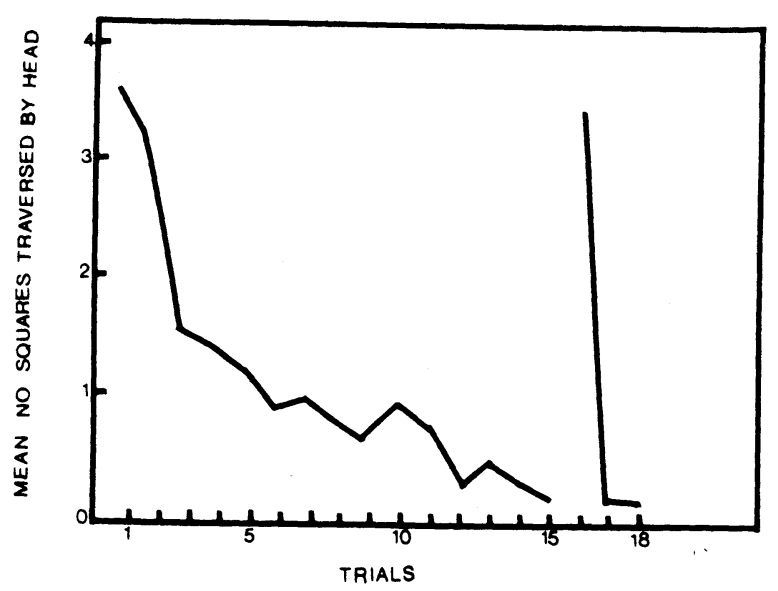

Figure 2. Mean number of squares traversed by the head as a function of trials within days.

produced dishabituation of the response to shadow. No significant dishabituation was found for either dependent variable (but see Andry \& Luttges, 1972). Hence, the fact that the dishabituation stimulus produces a strong response during its administration is no guarantee that dishabituation will occur. Using the terminology of Groves and Thompson (1970), this finding indicates that activation of a response system may not necessarily sensitize that system.

Since, in nature, shadow stimuli would most likely signal the approach of a predator to Thamnophis, the fact that habituation occurs might be seen as problematic, since decreased responsiveness is likely to be harmful. However, the resemblance between the natural situation and the present one is merely superficial. First of all, a predator is unlikely to appear with the frequency that the experimental shadow was administered to the present subjects (cf. Schleidt, 1961). Second, the pattern of stimulation presented by a predator from "trial to trial" is unlikely to be as constant as the stimuli employed in experimental situations (cf. Peeke, Wyers \& Herz, 1969). These two factors indicate that the garter snake's probability of habituating to a predator is extremely slight and that the present experiment should not be interpreted as demonstrating habituation to predator cues.

\section{REFERENCES}

Andry, M. L., \& Luttges, M. W. Neural habituation in garter snakes. Physiology and Behavior, 1972, 9, 107-111.

Goodman, D. A., \& Weinberger, N. M. Habituation in "lower" tentrapod vertebrates: Amphibia as vertebrate model systems. In V. S. Peeke \& M. J. Herz (Eds.), Habituation, Vol. 1, New York: Academic Press, 1973, Pp. 85-140.

Groves, P. M., \& Thompson, R. F. Habituation: A dual-process theory. Psychological Review, 1970, 77, 419-450.

Peeke, H. V. S., Wyers, E. J., \& Herz, M. J. Waning of the aggressive response to male models in the three-spined stickleback (Gasterosteus aculeatus L.). Animal Behavior, $1969,17,224-228$.

Russell, E. M. Changes in the behavior of Lebistes reticulatus upon a repeated shadow stimuli. Animal Behavior, 1967, 15 , 574-585.

Schleidt, W. M. Reaktionen von truthahnen auf fliegende Raubvogel und Versuche zur analyze ihrer A.A.M.'s. Zeitschrift fur tierpsychopologie, 1961, 18, 534-560.

(Received for publication December 7, 1974.) 